GONÇALVES, Valéria Portugal; ORTEGA, Francisco. Uma nosologia para os fenômenos sobrenaturais e a construção do cérebro 'possuído' no século XIX. História, Ciências, Saúde - Manguinhos, Rio de Janeiro, v.20, n.2, abr.-jun. 2013, p.373-389.

\title{
Uma nosologia para os fenômenos sobrenaturais e a construção do cérebro 'possuído' no século XIX*
}

\author{
A nosology for \\ supernatural phenomena \\ and the construction of the \\ 'possessed' brain in \\ the nineteenth century
}

Valéria Portugal Gonçalves

Doutora em Saúde Coletiva pelo Instituto de Medicina Social/ Universidade do Estado do Rio de Janeiro (IMS/UERJ). Rua São Francisco Xavier, 524,

pavilhão João Lyra Filho, 70 andar, blocos D e E 20550-900 - Rio de Janeiro - RJ - Brasil

goncalves.vp@gmail.com

\section{Francisco Ortega}

Professor-associado do IMS/UERJ.

Rua São Francisco Xavier, 524 ,

pavilhão João Lyra Filho, 7ำ andar, blocos D e E

20550-900 - Rio de Janeiro - RJ - Brasil

fortega2@gmail.com

Recebido para publicação em fevereiro de 2011.

Aprovado para publicação em abril de 2012.

\section{Resumo}

Fenômenos sobrenaturais como os chamados transe e possessão espiritual recebem, no final do século $\mathrm{XX}$, codificação científica, integrando os diagnósticos da psiquiatria hegemônica. No final do século XIX, observamos a apropriação científica de fenômenos considerados originários da superstição ou imaginação popular. Neste trabalho, demonstramos como o transe e a possessão espiritual foram estudados por Franz Anton Mesmer e seus discípulos ao desenvolver o conceito de magnetismo; por James Braid no processo de criação da teoria da hipnose; e por Jean Martin Charcot, marcando a entrada da histeria para as classificações nosológicas. Apesar das diferenças entre essas escolas, identificamos a utilização do cérebro e de metáforas cerebralistas como alicerce das teorias sobre a mente.

Palavras-chave: transe; possessão espiritual; mesmerismo; hipnose; histeria.

Abstract

At the end of the twentieth century, supernatural phenomena such as so called trances and possession by spirits received a scientific classification, which includes the numerous diagnoses of the dominant psychiatry. At the end of the nineteenth century we can observe a process of scientific categorization of phenomena considered to have originated in superstition or popular imagination. In this work we show how trances and spiritual possession were studied by Franz Anton Mesmer and his followers when developing the concept of magnetism; by James Braid during the creation of his theory of hypnosis; and by Jean Martin Charcot, which marked the entry of hysteria into nosological classification. Despite the differences between these schools, we identify the use of the brain and cerebral metaphors as the foundation of theories of the mind.

Keywords: trance; spiritual possession; mesmerism; hypnosis; hysteria. 
A partir da quarta edição do Diagnostic and statistical manual of mental disorder, DSM-4, (APA, 1994) aparece, dentro do grupo dos transtornos dissociativos, uma categoria diagnóstica denominada transtorno do transe de possessão. Como consequência, estados mentais complexos, como transe e possessão espiritual, que povoam a imaginação ou a superstição popular, ganham o estatuto de entidade nosológica, a partir das classificações diagnósticas oficiais da psiquiatria hegemônica. O transe e a possessão têm sido considerados estados dissociativos desde a terceira edição do DSM (APA, 1980), quando deixaram de fazer parte do grupo das histerias. Até a segunda edição do manual (APA, 1968), quando as teorias freudianas dominavam as explicações dos fenômenos, tais estados mentais, apesar de não textualmente mencionados, situavam-se na categoria neurose histérica tipo dissociativo.

A apropriação, por parte do discurso científico, de fenômenos de cunho religioso, cultural ou sobrenatural faz parte de um processo que se repete na história da ciência. Fenômenos ditos de clarividência, xenoglossia e mediunidade foram entendidos como bruxaria, estados magnéticos, estados hipnóticos e histeria em diferentes momentos de nossa civilização. Neste artigo apresentamos o processo de codificação do transe e da possessão produzido ao longo do século XIX, iniciando a partir da teoria do magnetismo animal, criada por Franz Anton Mesmer (1734-1815) e seus discípulos. Em seguida, abordamos a construção da teoria da hipnose por James Braid (1795-1860) e a codificação da histeria por Jean Martin (18251893), o que abriu definitivamente as portas da academia para esse fenômeno. O cérebro e metáforas cerebralistas constituíram denominador comum dessas teorias sobre a mente, na busca da naturalização de fenômenos considerados sobrenaturais.

\section{Do cérebro magnético ao cérebro hipnotizado}

O movimento mesmerista, criado pelo médico austríaco Franz Anton Mesmer na virada para o século XIX, foi alvo de inúmeros ataques e acusações de charlatanismo. Em virtude disso, era de interesse de seus membros investir em formas de obter aprovação científica para a doutrina. Para tal, foi necessário construir teorias que explicassem fenômenos considerados ocultistas, extáticos ou sobrenaturais, a partir de um vocabulário fisiológico que transformasse estados mentais decorrentes do transe mesmérico em fenômenos naturais, cujos mecanismos eram localizados no sistema nervoso.

Em sua divulgação pela Europa, esse movimento passou por oscilações de receptividade nos meios acadêmicos, até que, ainda no século XIX, atingiu sua derrocada final, sendo suas premissas, segundo alguns autores, recodificadas dentro do paradigma da hipnose (Bernheim, 1884, 1866; Sinnet, 1893; Oppenheim, 1985). Contudo, segundo Braid (1843), a hipnose constitui uma ruptura fundamental com o magnetismo. Estados mentais cotidianos, assim como os mais extraordinários, como os fenômenos de transe e possessão, foram descritos por meio de explicações eletrofisiológicas já comprovadas desde o final do século XVIII, por exemplo, o galvanismo e a teoria dos condutores. Tais explicações trouxeram contribuições fundamentais para consolidar uma concepção materialista da mente.

Ao criar um método muito particular e, por muitos, considerado excêntrico, Mesmer afirmava que poderia produzir curas de vários tipos de doenças empregando magnetos (Mesmer, 1779). Apoiava-se no suposto magnetismo entre os corpos celestes e na correspondente 
influência sobre nossos organismos (Alvarado, 2002; Gauld, 1992; Whorton, 2002; Mateo, 2004). Mais tarde, dispensou os magnetos e, segundo declarou, passou a usar seu próprio corpo e personalidade, configurando um método que nomeou de magnetismo animal. A teoria explanatória de Mesmer para seu tratamento baseava-se na existência presumida de um fluido etéreo, que serviria de meio de transmissão de influência dos corpos celestes sobre a Terra, passível de ser conduzido através do sistema nervoso humano (Whorton, 2002; Mateo, 2004). Esse fluido invisível seria responsivo ao magnetismo inerente ao operador ou magnetizador (Quen, 1976). Para Mesmer e seus discípulos, a saúde dependia do equilíbrio desse fluido vital no organismo. Seu fundador teve a reputação abalada após a reprovação de seu método por um parecer ${ }^{1}$ negativo emitido pelos comissários do rei da França em 1784.

O mais famoso discípulo de Mesmer, o marquês Chastenet de Puységur (1751-1825), foi um médico que buscou aplicar aos métodos magnéticos, desacreditados havia trinta anos, um vocabulário que pudesse convencer a academia médica a realizar nova avaliação. Endereçou aos membros da Faculdade de Paris um apelo para que examinassem tais teorias em função daquilo que acreditava ser argumento suficiente a considerar: as alterações fisiológicas de tais fenômenos. Em documento elaborado em 1811, utilizou teses de prestígio do passado, referindo-se principalmente às descobertas de Newton, que mereceram um capítulo inteiro em um de seus trabalhos (Puységur, 1811).

Ainda no prefácio de seu documento podemos ver as metáforas que ele considerou importantes para a difícil tarefa de explicar, por exemplo, o estado de sonambulismo ${ }^{2}$ que era, então, um dos fenômenos magnéticos mais curiosos e interessantes. Apoiou-se nas descobertas do galvanismo, concretizadas nas pilhas de Volta, para demonstrar que o magnetismo mineral ou a eletricidade seriam fenômenos resultantes de maior ou menor aceleração do movimento do fluido universal dentro do corpo. Desejoso de fazer crer que o magnetismo não se tratava de operação mística ou supersticiosa, Puységur (1811, p.239) afirmou:

Diga aos seres crédulos ou supersticiosos, iludidos pela aparente maravilha que creem sobrenatural, já que ignoram sua causa, que tais fatos não são mais do que simples manifestação da fermentação do fluido vital do homem que ocorre com frequência. ... Aquilo que os sábios, outrora, já suspeitavam, mas de cuja existência, com a ajuda do sonâmbulo, não se pode, hoje, duvidar. Ao entusiasta, operando misticamente ou de boa-fé, esses pretensos prodígios estão bem longe de ser resultado da influência de qualquer espírito familiar ou de qualquer divindade tutelar, cuja orgulhosa opinião que tenha de si mesmo os faça atribuir. ${ }^{3}$

Puységur evidencia, assim, que todos esses fatos, incluídos as convulsões e os estados catalépticos, obedecem, de acordo com a lei do ímã e da eletricidade, aos impulsos da vontade do seu magnetizador. A vontade não é apenas o agente motor, mas o excitador e modificador de todas as manifestações magnéticas, e, como quer provar, todos os fenômenos seriam fisiológicos, não passando, portanto, de fatos naturais (Puységur, 1811, p.240).

Deleuze (1826), também discípulo de Mesmer, considerava que, se os mesmos comissários que reprovaram seu mestre, tivessem refeito seu exame dez anos mais tarde, teriam reconhecido o poder da vontade, teriam observado o sonambulismo, do qual não tinham noção alguma, e, assim, teriam chegado a conclusões inteiramente diversas daquelas a que chegaram muito apressadamente. Afirmou que: "se os médicos fossem instruídos a respeito do magnetismo ..., 
[ele] teria conquistado seu lugar entre as ciências de fatos como a eletricidade; [o magnetismo] seria esclarecido pelas novas pesquisas sobre o sistema nervoso, que por sua vez as esclareceria" (p.10).

Sobre a teoria do fluido, Puységur (1809) apresentou a explicação dada por um de seus pacientes em sonambulismo. Quando seus pacientes se encontravam nesse estado, magnetizadores relatavam observar desproporcional incremento de suas faculdades mentais em relação a seu estado de vigília. Foi dessa forma que esse discípulo de Mesmer inaugurou uma nova maneira de adquirir conhecimento, deslocando o eixo do saber para a fala do paciente em estados magnéticos. Verificamos aqui que metáforas magnéticas e humorais convivem com um suporte cerebralista para o trajeto fluídico no corpo:

O magnetismo ... poderia ser chamado de óptica preliminar, pois, por meio dele, temos a faculdade de ver, de sentir, pressentir, julgar claramente efeitos, assim como ordenar, omitir e julgar definitivamente pelo ímã vital que chamamos vulgarmente de fluido animal. Esse restaurador é impelido pela vontade da alma, que é uma parte grosseira, posto que a alma que possuímos não é composta de qualquer matéria. Esse ímã é, então, imperceptível e do centro de nosso corpo é levado ao coração, e em seguida ao cérebro; é por esse domínio que nascem dentro de nós a vontade e a ação ... Quando estamos doentes, esse ser específico [o ímã] é interrompido pelos humores, que turvam e empalidecem a clareza preliminar. Os humores então chegam ao cérebro com rapidez; surgindo daí a congestão relacionada ao aumento de febre. É necessário impeli-los [os humores] com urgência se não queremos sucumbir. Para isso deve-se procurar um suplemento desse ímã para fortificar o indivíduo. Quando [em quantidade] suficiente, esse ímã é o senhor dos humores, os atinge com rapidez, reanima o sangue, e, por consequência, os remete ao equilíbrio (Puységur, 1809, p.201-202).

Outras interpretações de seguidores procuraram dar conta de sintomas excepcionais, como, por exemplo, as explicações de Léon L. Rostan (1790-1866), mesmerista francês que influenciou o movimento na Espanha:

o cérebro do magnetizador secreta um fluido muito semelhante ao elétrico. Esse agente não permanece aprisionado na pele ou nos músculos do magnetizador, mas flui para o exterior com certa força, criando uma atmosfera nervosa em torno dele. Essa atmosfera nervosa ativa do magnetizador mistura-se com a atmosfera nervosa passiva gerada pela vontade receptiva do paciente magnetizado. A mistura das duas atmosferas nervosas, na qual reside o rapport magnético, gera certo tipo de modificação no sistema nervoso do paciente e explica a comunicação dos desejos e vontades, e até mesmo o pensamento do magnetizador ao paciente magnetizado (Rostan citado em De Pablo, 2006).

Em muitos textos de magnetizadores, vemos uma oscilação de concepções materialistas/ imaterialistas. Havia momentos em que os fenômenos do sonambulismo eram tratados como um suposto estado especial em que o paciente estaria receptivo ao conhecimento dos mistérios da vida, podendo ocupar-se de ideias religiosas, da imortalidade, da independência da alma e fazer previsões do futuro do próprio magnetizador. Por outro lado, verificamos que esses mesmos magnetizadores, ao se reportar ao mundo acadêmico, procuravam tornar o abstrato algo compreendido dentro de razões fisiológicas. A variação de postura faz Cazeto (2001, p.157) afirmar que devemos relativizar essa naturalização. Para esse autor, o ideário do Romantismo - com a perspectiva de uma conexão do indivíduo com a totalidade do 
mundo - permitiu uma tolerância aos raciocínios fronteiriços entre o misticismo e a ciência, inexistente nos dias de hoje.

Segundo Oppenheimer (1985), o mesmerismo inicialmente explicava seus métodos extraordinários em termos físicos e sobreviveu à incompreensão durante certo tempo graças à aceitação científica posterior do papel da imaginação e sugestão, dando à mente predominância sobre o corpo. O sensacionalismo que girava em torno das curas de Mesmer não obscurecia a qualidade comum de sua teoria, ao menos da perspectiva de seus contemporâneos. Para Oppenheimer, assim como outras cosmologias do final do século XVIII, não havia nada de original a respeito do fluido magnético e sutil de Mesmer. Esse século era repleto de fluidos - universal, vitalista, mecanicista, animístico, sutil, magnetizado e elétrico. A teoria de Mesmer era apenas uma das muitas que confiantemente propunham oferecer uma visão da realidade física fundamental. Com a ampliação do movimento mesmerista no século XIX, as implicações mentais do magnetismo animal começaram a atrair a atenção da profissão médica. Nesse sentido, o hipnotismo ofereceu, segundo Oppenheim, uma saída para o movimento ao libertá-lo de suas associações com o ocultismo, recebendo finalmente status científico respeitável. Os primeiros estádios dessa transformação gradual surgiram dos trabalhos de James Braid (Oppenheim, 1985).

Nem todos concordam com essa análise. Sinnett (1893) afirma que Braid denegriu a fonte de onde havia tirado suas conclusões - não tão inéditas como tão prontamente proclamava - ainda que tenha realizado um serviço de utilidade pública, por tornar acessível uma ferramenta terapêutica tão valiosa. Braid teria sofrido acusações de plágio, as quais ele mesmo menciona em seus textos (Braid, 1843). Uma delas é a de que teria retirado do mesmerista indo-português José Custódio de Faria, conhecido por abade Faria (1746-1819), a noção de que a causa do magnetismo residia no próprio paciente, e não na vontade do magnetizador (Sinnet, 1893; Bernheim, 1884, p.60). Alguns autores argumentam que é possível reconhecer na prática do abade Faria os primórdios da noção de sugestão (ao menos como mecanismo de produção de sonambulismo) utilizada por Braid (Sinnet, 1893; Bernheim, 1884), aperfeiçoada por Ambroise Auguste Liébeault (1823-1904) e posteriormente desenvolvida por médicos da Escola de Nancy - da qual Hippolyte Bernheim (1840-1919) foi o maior expoente.

O cirurgião escocês James Braid ${ }^{4}$ ficou conhecido por sua tentativa de descobrir no magnetismo o fundamento neurofisiológico de seus efeitos sobre o estado mental dos pacientes. Distintamente, porém, das alegações de Openheimer e Sinnet, Braid afirmou que o hipnotismo representava uma ruptura em relação ao magnetismo animal. Na época em que escreveu seu trabalho, não recebeu nenhum crédito. Só depois de sua morte é que seu método foi finalmente submetido ao exame de membros da academia (Cazeto, 2001). O que parece mais interessante em suas pesquisas é a tentativa de provar que nada havia de sobrenatural na terapêutica mesmérica utilizando-se da neurofisiologia para melhor explicá-la dentro de um modelo científico compreensível. A sua intenção de distinguir a hipnose ${ }^{5}$ do mesmerismo o levou a declarar a "neuroipnose" um novo método "inteiramente separado do magnetismo animal" (Braid, 1843, p.4). Em certo momento afirmou que a descoberta de um novo agente para o fenômeno tornou-o capaz de desenvolver um método mais eficaz.

Sobre os estados alterados que comumente acompanham os pacientes hipnotizados, Braid (1843, p.XII) declarou em seu livro: 
Há marcante diferença nos graus de susceptibilidade dos indivíduos à influência hipnótica, alguns se tornando rápida e intensamente afetados, outros apenas lenta e levemente alterados. Essa diferença de susceptibilidade é análoga ao que experimentamos em relação aos efeitos de medicações em indivíduos diferentes e, sobretudo, como visto no caso de vinho, ópio e óxido nitroso.

Braid (1843, p.XIV) apresentou algumas comparações entre os sintomas hipnóticos e os efeitos de substâncias químicas sobre o sistema nervoso. Destacou, como resultado do ópio assim como do hipnotismo, o estado mental em diferentes estádios:

Em um estádio, o hipnotismo provoca extraordinário poder de concentração de pensamento, ou disposição para contemplação, assim como, em outro, as faculdades discursivas e as imaginativas são excitadas ao máximo, e, então, as mais expandidas e brilhantes cenas e imagens se apresentam à imaginação febril. Tais efeitos são análogos aos descritos como resultantes do uso de ópio, detalhados por sir Humphry Davy, que experimentou, ele próprio a inalação de óxido nitroso.

Segundo o autor, se os efeitos produzidos pela hipnose eram análogos aos produzidos por agentes químicos, de essência material, então a suposição de que o magnetismo se apoiava na vontade ou no olhar do magnetizador estava partindo de uma falsa concepção. Tal fato falava a favor da verossimilhança de sua tese e, assim, da ideia de que tudo não passava de efeitos fisiológicos sobre o sistema nervoso (Braid, 1843). Uma preocupação constante em seu trabalho era o grande preconceito relativo ao mesmerismo decorrente dos riscos de ele ser utilizado para fins imorais. Não é demais lembrar que no famoso relato da Comissão Real, que reprovou o mesmerismo em 1784, constava uma terceira e secreta versão solicitada pelo rei sobre o suposto potencial de usos e abusos eróticos das pacientes indefesas em estado magnético (Quen, 1976). Quanto a esses riscos de ofensa à moral dos pacientes, Braid (1843, p.10) afirmou que na hipnose, da maneira como era induzida pelo método explicado por seu tratado, não havia motivo para censura:

Tenho provado pelos experimentos, tanto em público quanto privados, que durante o estado de excitamento o juízo é suficientemente ativo para tornar o paciente, se possível, ainda mais difícil de ser conduzido do que na condição desperta e no estado de rigidez e insensibilidade. Os pacientes retornam ao estado de mobilidade, e de sensibilidade exaltada, se forem rudemente manuseados ou ainda por intermédio de um sopro de ar. Nem mesmo é necessário que isso seja feito pela pessoa que o colocou no estado hipnótico ... E, finalmente, o estado ["neuroipnótico"] não pode ser induzido, em qualquer estádio, a não ser com o conhecimento e o consentimento da parte operada. Isso é mais do que se pode dizer a respeito de um grande número de nossas mais valorosas medicações ..., já que existem muitas que temos o hábito diário de utilizar ... e que podem ser administradas sem o conhecimento da suposta vítima.

Ao assistir às demonstrações do mesmerista francês Charles Lafontaine (1803-1892) em visita à Inglaterra, Braid (1843, p.35) não deixou de lado todos os seus preconceitos a respeito do método, mas, na segunda demonstração, algo lhe chamou atenção: a incapacidade de o paciente abrir os olhos mesmo ao ser instruído a fazê-lo. Convenceu-se de que essa inabilidade não era atribuída a nenhuma das causas referidas nos trabalhos que havia lido sobre mesmerismo. 
É lei da economia animal que, por contínua fixação visual e mental, em qualquer objeto de natureza não excitante, com absoluto repouso do corpo e quietude geral, [os pacientes] se tornam enfastiados, o que lhes dá ... a sensação de estupor, que logo irão experimentar ... Durante tal experimento um estado de sonolência é induzido e acompanhado pela condição do cérebro e do sistema nervoso em geral, que leva o paciente afetado - de acordo com o modo de manipulação - a exibir o fenômeno hipnótico. Como o experimento ocorre também com cegos, não considero que a impressão seja feita tanto pelo nervo óptico, mas através dos nervos sentiente, motor, simpático, e através da mente (p.31).

Braid (1843) acreditava que o fenômeno da hipnose era induzido apenas por uma impressão feita nos centros nervosos pela condição física e psíquica do paciente, sem o concurso de qualquer agência. Segundo Braid, esta não ocorreria nem por excitação produzida pela ação de um hipnotizador, já que qualquer um poderia auto-hipnotizar atendendo estritamente às regras simples por ele estabelecidas. Em certo trecho de seu livro, procurou esclarecer que não acreditava ser a mente algo que se pudesse reduzir ao cérebro. Para defender sua posição, utilizou a metáfora de que a mente seria um músico que necessita de seu instrumento, o cérebro, para reproduzir sua obra (p.76). Mais tarde, suas pesquisas o levaram a investigar, mais a fundo, o fato de que ideias sugeridas durante a hipnose poderiam tratar crenças ou ideias patológicas, que considerava causadoras de doenças. Dessa forma, alguns autores identificaram uma mudança de rumo em suas pesquisas, ao privilegiar o aspecto psicológico da hipnose (Roudinesco, 1994; Bernheim, 1884; Cazeto, 2001).

Conforme análise de Roudinesco (1994), o trabalho de Braid conferiu honra às pesquisas sobre hipnose, indo ao encontro das então recentes descobertas anatomopatológicas e de localização cerebral. A partir desses trabalhos, essa terapêutica pôde receber nova definição e ser retomada por Charcot, Bernheim e Liébeault. A teoria fluídica foi refutada e substituída pela noção físico-químico-psicológica. Para Braid, tudo se passava no cérebro do sujeito sem a força exterior imaginada pelos magnetizadores (Cazeto, 2001).

\section{A cerebralização inconsciente e a histeria cerebral}

O hipnotismo chegou à França por intermédio de Eugène Azam (1822-1899), cirurgião que, ao se deparar com um caso bastante peculiar de histeria, tentou repetir os feitos de Braid, buscando elucidação para o que se configurava como um verdadeiro enigma para ele e seus contemporâneos. Tratava-se da famosa paciente Félida X., cujos sintomas se assemelhavam às várias descrições então vigentes de dupla personalidade. Chamava-lhe a atenção o fato de Félida, além de apresentar todos os sinais de histeria, às vezes exibir um estado que Azam (1887, p.106) preferiu chamar de "uma segunda condição". Nesse estado era acometida de mudança de temperamento que alterava seu caráter do usual teor melancólico para um temperamento alegre e, em outros aspectos, bastante diferente do primeiro. A transição entre os dois estados era sempre precedida de dores de cabeça e de uma espécie de sono. Perguntada sobre o que acreditava ser o seu mal, ela nunca afirmou ter a impressão de ser outra pessoa. Distintamente de casos semelhantes, em uma das condições (ou um de seus estados), era perfeitamente capaz de lembrar-se de "suas duas vidas". De acordo com Azam, seu caso não 
corresponderia aos numerosos estados relatados por outros médicos da época como de dupla personalidade ou de dupla consciência. Azam defendeu que Félida, na verdade, padecia de amnésia temporária, e a ideia de que a paciente teria duas vidas seria apenas uma ilusão que a ausência de lembranças poderia provocar ao observador.

Azam comparou esse caso com o que havia experimentado das pesquisas de Braid sobre hipnose no estado de sonambulismo. Tal como os pacientes hipnotizados, Félida também não conseguia lembrar o que ocorria durante seus acessos (em uma das condições). Apesar dessa amnésia, Azam observou uma diferença que considerou fundamental: a paciente durante seus acessos (quando experimentava o que chamamos hoje de "outra personalidade") não mostrava os sintomas de anestesia ou hiperestesia típicos do sonambulismo. Em seu estado usual, contudo, esses sintomas eram exibidos pela paciente. Assim Azam distinguiu o caso de Félida do sonambulismo e postulou que a histeria poderia ser explicada por uma alteração de memória. Para a hipótese da alteração de memória, tinha explicação fisiológica, com base nas experiências de Claude Bernard (1813-1878) e de Jules Bernard Luys (1828-1897), que estabeleciam uma relação da ação da circulação sobre as funções cerebrais (Azam, 1887, p.121). De acordo com esses dois autores, o aumento do afluxo de sangue levaria a uma excitação das funções do cérebro, e sua diminuição, à calma e ao repouso. O sono provocado pela diminuição da circulação seria causado pelo retraimento temporário dos vasos que aportam sangue ao cérebro. Daí Azam (1887, p.122) fazer esta analogia:

Tomemos como exemplo uma função cuja localização parece certa. A função da linguagem articulada. Então! Se os vasos que conduzem sangue para a terceira circunvolução do lobo anterior esquerdo têm seu calibre diminuído, essa função será alterada, e as outras permanecerão intactas. Da mesma maneira, se a memória é abolida, temos o direito de pensar que essa alteração seja devida a uma diminuição do aporte sanguíneo para as partes do cérebro cuja integridade e perfeição orgânica devam ser indispensáveis ao funcionamento da memória.

Em resumo, Azam (1887, p.122) afirmava que a amnésia de sua paciente tinha como causa a diminuição momentânea e periódica do afluxo de sangue a certas partes do cérebro. Estimava, além do mais, que esse retraimento momentâneo dos vasos fosse devido ao estado de histeria da doente, estado que teria ação sobre os elementos contráteis desses canais.

Ao repetir as experiências de Braid, Azam (1887, p.13) negou ter testemunhado qualquer um dos fatos "maravilhosos do magnetismo", porém afirmou que essas pesquisas o ajudaram a compreender como esses fenômenos poderiam ser reproduzidos. De acordo com Cazeto (2001), as pesquisas de Azam teriam influenciado pesquisadores da época a associar o fenômeno da divisão da personalidade à histeria ${ }^{6}$, inaugurando a noção de que tal divisão se devia a uma alteração da memória e desviando a atenção da sugestionabilidade para a fisiologia. Além disso, ao trazer o hipnotismo para a França ajudou as Escolas de Salpêtrière e de Nancy a naturalizar os fenômenos do magnetismo, naquela os enquadrando em uma tabela nosológica sistemática, cujo principal autor foi Jean Martin Charcot; nesta, negando seu fator patológico, conforme postulado por Bernheim e seus discípulos. Ambas as escolas, porém, promoveram uma redução das noções mentais para a fisiologia cerebral.

Outra importante linha de estudos sobre a memória advinha das pesquisas de Théodule Ribot (1839-1996), que se interessava por casos como aqueles em que alguém não se reconhecia 
como autor de eventos que outros lhe contavam ter realizado - sugerindo a existência de mais de um personagem no mesmo sujeito. Segundo Ribot (1881), a memória seria apenas um caso particular de um evento maior, cujas raízes penetrariam a vida orgânica. Assim como Azam, ele também classificava os casos mais complexos de double conscience, que tiveram ampla divulgação nos anos 1880 como amnésia temporária. Em sua teoria, a memória não seria o único apoio do eu. Haveria ainda outra base: a percepção de nosso próprio corpo, de seu funcionamento, e essa cenestesia seria o suporte da memória, por sua vez, um fragmento consciente dessa percepção mais ampla do funcionamento vital. Essa percepção maior conteria, além da memória, um componente obscuro - somados, esses componentes corresponderiam ao modo total como viveríamos essa impressão (p.83-85). Algo como um "sentimento de vida", cuja repetição lhe daria um lugar abaixo da consciência e que estaria na base da personalidade. Desse modo, o eu seria formado pela memória, mas se apoiaria na percepção das funções vitais (Cazeto, 2001).

Conforme explicação de Ribot (1881, p.25), "a atividade nervosa é muito mais extensa do que a atividade psíquica: toda reação supõe uma ação nervosa, mas a recíproca não é verdadeira". O estado de consciência seria, de acordo com o autor, um estado particular do sistema nervoso, não sendo a ação nervosa um acessório, mas uma parte integrante do evento perceptivo:

ela é a base, a condição fundamental; desde que se produz, o evento existe nele mesmo; desde que a consciência se ajunte, o evento existe por ele mesmo; a consciência o completa, mas não o constitui. Se uma das condições do fenômeno faltar, seja a intensidade, seja a duração, sejam outras que nós ignoramos, uma parte - o processo consciente - desaparece; outra parte - o processo nervoso - subsiste. Nada mais resta ao evento senão sua fase puramente orgânica. Nada de estranho, portanto, se mais tarde os resultados desse trabalho cerebral reaparecem: ele ocorreu de fato, ainda que nada o tenha constatado. Isso compreendido, tudo o que se relaciona à atividade inconsciente perde seu caráter misterioso e se explica sem complicações (Ribot, 1881, p.25).

Com essas noções, Cazeto (2001) acredita que Ribot naturalizava processos mentais que eram considerados exclusivos do espírito e avaliados como superiores. De certo modo, para Cazeto, Ribot reduzia o psíquico ao somático, ao explicar o anímico por meio da fisiologia. Essa tese leva-o a desenvolver o conceito de personalidade física como uma espécie de representação dos estados somáticos, sendo o eu uma decorrência dessa representação com base em sua constituição física. Assim, justificou as variações de personalidade em consonância com as alterações somáticas e os respectivos efeitos produzidos sobre a identidade.

Se, pois, se admite que as sensações orgânicas vindas de todos os tecidos, de todos os órgãos, de todos os movimentos produzidos, em uma palavra, de todos os estados do corpo, são representadas em um grau qualquer e sob uma forma qualquer no sensorium, a personalidade física não é nada mais do que o seu conjunto, segue-se que ela deve variar com as sensações orgânicas e que estas variações comportam todos os graus possíveis, do simples mal-estar à metamorfose total do indivíduo. Os exemplos de dupla personalidade, de que se fez grande barulho ... não são senão um caso extremo (Ribot citado em Cazeto, 2001).

Cazeto (2001) observa que também no século XIX a noção do fator hereditário ganha relevo, e a de família patológica parece derivada da laicização de antigas noções religiosas. 
O trabalho de Ribot L'hérédité psychologique versou justamente sobre essas noções da hereditariedade, com descrição de estados patológicos e seu potencial de transmissibilidade entre gerações de familiares. Inicialmente Ribot (1894, p.138), ao apresentar suas análises, reforçou suas convicções de uma assunção organicista para os estados mentais. Mostrou que as doenças são transmissíveis, como todos os caracteres de estrutura externa ou interna, como todos os modos variados de organização do estado normal. E que a mesma questão se aplicava à ordem psicológica.

A transmissão da anomalia psicológica de todos os tipos, seja de paixão, seja de crime ou de loucura, foi admitida como lei mais genérica de mórbida hereditariedade psicológica. Segundo Ribot, todos os estados mentais tinham causa orgânica. De acordo com os alienistas, "a loucura pode ter causas puramente psicológicas tal qual se comprova através dos resultados da fisiologia, da patologia, das observações clínicas e microscópicas; tudo concorre para arruinar a tese de que a loucura necessariamente decorre de alterações dos órgãos e que as causas que a produzem pertencem à ordem de fenômenos completamente estranhos às leis da matéria" (Leuret citado em Ribot, 1894, p.139). Em resposta, Ribot (1894, p.139) registrou que, apesar dessas afirmações categóricas, a tese de Leuret vinha encontrando cada dia menos simpatizantes, "até mesmo entre os filósofos":

É que no fundo ela [a tese de Leuret] repousa sobre nossa ignorância e nossa impotência, limita-se a afirmar que, em vários casos, não existem causas físicas, já que não as vemos. Além dos limites que o poder do microscópio não ultrapassa, porém, se produzem os fenômenos que, apesar de não apreciáveis por nossos sentidos, não são menos materiais. Além disso, a ideia de uma doença do espírito independente de todas as causas orgânicas é tão ininteligível, que os próprios espiritualistas a rejeitam. ... Já que a loucura tem por causa imediata alguma afecção mórbida do sistema nervoso e que todas as partes do organismo são transmissíveis, é claro que a hereditariedade das afecções mentais é a regra. Se consideramos o pensamento como simples função do sistema nervoso ou, ao contrário, o sistema nervoso como simples condição do pensamento, isso não importa aqui.

Em seu trabalho, Ribot relatou inúmeros casos de famílias nas quais gerações repetiam integralmente as doenças mentais ou manifestavam outras patologias, também de natureza mental. Entre eles estão as alucinações simples (sem alienação), em que o paciente não tinha outro sintoma senão o fato de ver fantasmas - havendo, na maioria dos casos, relato de familiares com esse sintoma. No célebre La Visionnaire de Prévorst Kerner conta a história e os fenômenos de 'visões' extraordinárias experienciadas pela maior parte dos membros da família Hauffe. Um dos irmãos teria manifestação menos grave e sem complicações dos fenômenos de êxtase e de catalepsia da visionnaire.

Uma forma de monomania desaparecida, hoje mais rara, mas que estaria ainda muito florescente há três séculos, é aquela da possessão ou 'demoniomania'. Essas histórias que não parecem mais do que sonhos hoje em dia antigamente ... constituíam uma realidade cruel e absurda. A possessão era considerada um crime pelos tribunais da época cuja pena era o suplício. Essa afecção mental, qualificada então de sobrenatural, na verdade se transmite pela hereditariedade (Ribot, 1894, p.147).

Outro estudioso que teve vital importância no modo de o eminente médico francês Jean Martin Charcot pensar e classificar a histeria foi Paul Briquet (1796-1881), autor de Traité de 
l'histerie, obra considerada a primeira sistematização da doença e responsável finalmente pela disseminação da sua noção cerebralista. Briquet (1859) dedicou, no final da terceira parte de seu livro, um capítulo à anatomia patológica da histeria, no qual construiu cuidadosamente sua teoria. Analisou vários relatos de estudos de anatomia patológica realizados por outros autores em mulheres histéricas, em que os órgãos examinados eram principalmente os ovários e o útero. Com isso, procurou demonstrar que estava equivocada a ideia clássica de a histeria ser uma desordem dos órgãos sexuais, constatando que as lesões encontradas nesses órgãos poderiam ser encontradas em qualquer paciente que tivesse morrido de outras causas. Acresce a isso o fato de ter presenciado casos de histeria em pacientes do sexo masculino.

Dada a inespecificidade dos achados pos-mortem relativos a esses órgãos, optou por verificar a hipótese de Charles Le Pois (1563-1633) e Thomas Willis (1621-1675), autores que no século XVII, haviam chegado à conclusão de que a histeria tinha sua razão anatômica no encéfalo. Sua impressão não teve muita receptividade naquela época em que somente os órgãos genitais eram examinados nos estudos de anatomia patológica da histeria (Briquet, 1859). ${ }^{7}$ Quanto às alterações encontradas no cérebro de pacientes que morreram de ataques histéricos, Briquet afirmou que não podia ter conclusões precisas, mas, tendo em vista as alterações flegmásicas frequentes que encontrou, entendeu que existiria entre a histeria e a meningite tal ligação, que seria difícil não estabelecer relação direta entre ambas. "Em resumo, até hoje a anatomia não explica nem a sede, nem a natureza da histeria; tudo que podemos supor é a existência de certo grau de congestão sanguínea em diversas partes do encéfalo ou de seus principais prolongamentos, congestão que poderíamos considerar como nada mais do que um acompanhamento de certos fenômenos histéricos" (Briquet, 1859, p.552).

O médico concluiu dessa análise que os estudos cadavéricos não podiam demonstrar que a histeria dependesse de uma lesão material. Esses estudos tinham por objetivo a exploração de partes que seriam a sede de fenômenos histéricos prolongados e não meras consequências orgânicas dos ataques em sua fase aguda. Os resultados, porém, provaram apenas que os fenômenos eram dinâmicos e que não dependiam de qualquer lesão material apreciável (Briquet, 1859, p.552-553). Curioso é que, apesar dessa constatação de 'falta de materialidade na histeria', Briquet nunca deixou de se referir ao cérebro para explicar o fenômeno histérico. No final das análises das pesquisas anatomopatológicas, demonstrou sua preocupação quanto à indefinição de um substrato orgânico para a doença. Perguntava se a materialidade da histeria seria análoga ao fluido nervoso, como resultado de ações elétricas, ou se a histeria teria lesão que escaparia a nossos sentidos. Ou se, então, seria semelhante às ondulações do calor ou da luz. Terminou sua divagação com o que pareceu ser sua solução pragmática para esse impasse: "qualquer que seja a consideração dessa ausência de lesão material não pode ser indiferente para o tratamento; ela servirá para compreender como ocorre que simples modificadores da sensibilidade possam agir tão poderosamente sobre um grande número de fenômenos principais da histeria qualquer que seja sua duração" (Briquet, 1859, p.553).

\section{Da histeria cerebral ao cérebro 'possuído'}

Uma das inúmeras vezes em que Briquet utilizou o cérebro para desvendar a doença histérica foi em sua abordagem dos fenômenos extáticos. Briquet afirmou que os estados de 
êxtase são estados histéricos com excitação cerebral levada a tal ponto, que a ação concentrada sobre um só objeto produziria a abolição temporária das demais sensações e de outros movimentos temporários. Tais estados provocados pela concentração do espírito sobre um objeto não seriam raros na época, típicos do unidirecionamento das ideias religiosas da vida no claustro, sendo muito comum nas mulheres. Desse modo, pareciam razoáveis ao autor os numerosos casos de fenômenos extáticos de mulheres que haviam recebido a reputação de santidade ou beatitude. Assim, explicou os casos históricos de Elisabeth da Hungria, em 1207; Santa Gertrudes, em 1281, e Santa Brigitte, em 1343; Santa Catarina de Siena, em 1347; Joana d'Arc, Santa Teresa e Madame de Chantal, em 1572; Maria d'Ágreda em 1630; Madame Guyon, a correspondente de Fénelon, em 1688; e outros casos considerados de êxtase religioso e às vezes assim santificados (Briquet, 1859, p.409).

Briquet (1859, p.409) considerou o êxtase algo inerente à maior parte das grandes epidemias de histeria que ocorreram nas casas religiosas e nos locais em que o "excesso de prática devocional" e o "abandono às ideias místicas" tinham papel importante nesse processo. Segundo o autor, as convulsionárias de Cevenne eram um dos numerosos exemplos: "algumas caem ao chão, perdem a consciência, tremem todos os seus membros e se põem a rezar e a fazer predições, apenas uma termina, e outra cai ao chão e começa seu processo, às vezes, duas ou três caem ao chão simultaneamente" (p.409).

Assim como acreditava que a histeria tendia a melhorar na idade madura, "quando a idade avançada amortece-lhes a sensibilidade", Briquet (citado em Cazeto, 2001, p.244) também atribuía esse prognóstico aos casos de histeria com ataques extáticos (Briquet, 1859, p.410). $\mathrm{O}$ autor observou que esse tipo de ataque podia adquirir duas formas: algumas vezes era precedido de prelúdios ordinários de ataques de espasmo ou de convulsão histérica, de maneira que o êxtase não seria senão um dos incidentes do ataque; em outra forma, o paciente caía bruscamente em êxtase sem qualquer manifestação de pródromos.

A análise que Briquet fez do processo patológico pelo qual passava o paciente de histeria muito se assemelhava às descrições de Braid da indução hipnótica. Sem dúvida o paradigma da hipnose mostrou-se pregnante no pensamento científico da época. Por último, Briquet reforçou sua posição contrária às antigas noções de genitalidade para a histeria, teoria que, apesar de desfocada a partir de então, nunca deixou de constar do pensamento de Charcot, ao menos como sintoma acessório da doença (Cazeto, 2001; Roudinesco, 1994).

Como vimos, Charcot entendia os fenômenos histéricos, assim como as questões de dupla personalidade, sempre em comparação com seu sistema nosológico. Atentemos agora para uma 'receita' de Charcot, reproduzida por seu discípulo Paul Richet (1881, p.303-304), de um tipo especial de histeria:

Suponha um segundo período dentro do qual todos os fenômenos, os mais estranhos, que constituem o que chamamos de clownismo se multiplicam à vontade. Adicione o furor, a crise, a raiva, os movimentos desordenados, que já descrevemos igualmente entre os signos desse segundo período. Tome todos aqueles que, dentro dos outros períodos do ataque, apresentem algo mais ou menos extraordinário ou marcado pela predominância de elementos dolorosos, como as contraturas generalizadas, ou qualquer alucinação horrível do terceiro período. E você terá assim constituída uma variedade de ataque propícia para inspirar, com o passar dos tempos, a crença, o horror ou a comiseração. E 
exatamente nesse ponto um tipo de fantasia. Esses ataques que encontramos em nossa realidade ... são os que o senhor Charcot qualificou de demoníacos.

Richet (1881) analisou a demoniopatia segundo a conhecida classificação da histeria feita por Charcot em seus quatro períodos. No primeiro período, uma fase epiléptica era sempre facilmente reconhecível; o clownismo é marcado pelo batimento de pálpebra e ondulação do ventre em tremor parcial (p.304). No segundo período, as contorções com o corpo inteiramente retorcido em várias posições mostram os membros em extensão, que, se elevando perpendicularmente ao leito, se entrecruzam frequentemente por adução forçada (p.305). No terceiro período, a contratura costuma persistir, ainda que possa ser curta e incompleta. No quarto período, a doente volta a si, mas a contratura não desaparece; a crise de dor dilacerante a faz suplicar alívio aos assistentes. Em resumo, vê-se que esses tipos de ataques são particularmente caracterizados pela predominância da contratura dolorosa, pelo desenvolvimento de atitudes ilógicas ou contorções que lhes dão o aspecto assustador dos antigos possuídos (Richet, 1881, p.308).

Uma vez descrito o quadro, passemos às pesquisas neurofisiológicas realizadas na época, que forneciam os modelos explicativos dos fenômenos observados por esses profissionais. Lembremos que, segundo Charcot, a hiperexcitabilidade neuromuscular observada nas pacientes histéricas era uma aptidão particular do músculo à contratura, fácil de se evidenciar por constituir uma espécie de prova anatomofisiológica. Esse fato garantia ao observador segurança em relação aos riscos de simulação por parte do paciente. Ao pesquisar a letargia, Charcot descobriu nessa hiperexcitabilidade um fenômeno reflexo dos estados mais primitivos do sistema nervoso, o que permitiu mais tarde avançar sobre os fenômenos mais complexos de processos cerebrais superiores (Binet, 1889).

$\mathrm{Na}$ catalepsia, os reflexos cerebroespinhais estariam em sua máxima força, dando lugar, então, ao estado de contratura, que permitiria aos músculos permanecer, durante longo tempo na posição que se lhes dá, proporcionando um poder de contração capaz de vencer qualquer resistência imposta. Diz-se que, de fato, seria possível suportar o corpo sobre dois pontos extremos, e que, ainda que se lhe aplicasse uma carga mais pesada, ele não cederia à contratura. Dessa forma, fica explicada a estranha postura de opistótono - todo o corpo contraído em forma de arco - que frequentemente se vê nas histéricas em catalepsia e, por conseguinte, nas contorções demoníacas. Na letargia, a paradoxal hiperexcitabilidade neuromuscular poderia ser explicada apenas por um exagero considerável dos reflexos medulares, fazendo parecer que o cérebro inteiro tivesse sido atingido pela inércia (Cullerre, 1887).

No estudo do comportamento automático da catalepsia, Charcot (1889) observava uma particularidade do paciente em assumir posturas e posições de seus membros conforme seu médico o colocasse, tal qual um manequim. Tal fenômeno também era descrito pelos mesmeristas nos pacientes magnetizados (Bernheim, 1884). Charcot identificou uma função integradora superior, uma vez que a fisionomia dos pacientes também acompanhava o gesto imposto. Por exemplo, ao se colocar o paciente sonambúlico em posição de prece, ele não tardava em manifestar ideias religiosas, o mesmo ocorrendo com outras posturas, como a de luta ou a de agressividade (Charcot, 1889; Binet, 1889; Cullerre, 1887). Charcot concluiu por uma função automática do cérebro a qual deu o nome de automatismo cerebral ou cerebração inconsciente, expressão que Cazeto (2001, p.282) alega ter vindo de Ribot. 
Outro discípulo de Charcot, Gilles de la Tourette (1857-1904), descreveu os signos da possessão diabólica como sendo de histéricas stigmatas permanentes. Para ele, na histeria em sua forma geral, existiria um fundo comum sobre o qual evoluiria um conjunto de fenômenos constitutivos da afecção. Esse fundo comum, que se poderia designar concretamente como estado geral histérico - reservando o temperamento, por considerar mais particularmente o lado psíquico - seria formado pela reunião de um grande número de elementos. Esse conjunto ainda não seria completo, mas um laço comum os reuniria: a tenacidade, que fez com que Charcot o nomeasse de stigmatas permanentes. As stigmatas permanentes podem ser divididas em somáticas e psíquicas. Entre as primeiras, as mais frequentes seriam as alterações de sensibilidade - anestesia e hiperestesia. A anestesia é a que recebe mais atenção no trabalho de Tourette (1895).

Tourette dedicou-se às stigmatas diabólicas. Entre os signos de possessão reconhecidos pela Igreja, como elevação do corpo no ar, a faculdade de falar e de compreender as línguas estrangeiras, encontrar-se-iam as marcas que o demônio imprime no corpo dos possuídos. Para o autor, esses estigmas diabólicos se encontravam revelados em história de possessões em frequência igual à das anestésicas histéricas. Na autobiografia da madre superiora Joana de Anges, das ursulinas de Loudun, publicada por Charcot, há também relato de formigamento. Essa religiosa, às vezes, tinha o corpo todo queimado. De hemianestésica ou hiperestésica, Joana de Anges tornou-se anestésica total. Algumas noites passava em cubas de água congelada; outras, despida na neve; às vezes, se atirava em espinhos, de maneira que era encontrada toda rasgada ou rolando em urtigas a noite inteira (Tourette, 1895).

No estudo complementar aos Études cliniques sur l'histéro-épilepsie ou grande hystérie, intitulado Les démoniaques dans l'art, Charcot e Richet propõem-se a mostrar o lugar dos acidentes da neurose histérica na arte, numa época em que não seriam considerados doença, mas uma perversão da alma devida à presença do demônio e suas manobras. Optaram pelo que consideravam um estudo de medicina retrospectiva, como os que já haviam sido realizados por Louis Florentin Calmeil (1798-1895), Émile Littré (1801-1881) e outros, mas com a novidade de que o fizeram a partir de documentos ilustrados (Charcot e Richet, 1887). $\mathrm{O}$ auge desse estudo parece ser a obra de Rubens Saint Ignace guérissant les possédes (Museu de Viena), reproduzida em gravura. Para os autores, aí se encontram as características mais notórias do grande ataque:

seria impossível reunir em uma figura signos mais assustadores que caracterizassem a grande neurose. Do século XVII e XVIII, a obra nos conduz às demoníacas de hoje, ou seja, homens e mulheres vítimas da grande histeria. Haveria sob a incoerência aparente uma razão que surge de um processo mórbido ... da mesma maneira como sucede o agrupamento de todos esses fenômenos, encontramos as marcas indiscutíveis de uma ordem preestabelecida, a constância e a inflexibilidade de uma lei científica (Charcot e Richet, 1887, p.956).

Na medicina francesa, outras pesquisas contribuíram para formar o pensamento da época sobre a histeria. Nos experimentos de Charcot já era possível identificar uma mudança gradual em suas concepções sobre a mente e estados de divisão do eu, com o surgimento de noções psicológicas. A Escola de Charcot (Salpêtrière) saiu derrotada na rivalidade com a de Nancy, mas alguns elementos de seus estudos certamente contribuíram para a constituição 
do famoso debate entre Freud e Janet, na virada para o século XX. A polarização entre as teorias da dissociação e as noções do conflito inconsciente ganharam destaque no meio científico, e os fenômenos extraordinários permaneceram no terreno da histeria, durante quase todo o século XX, com a vitória da teoria freudiana.

\section{Considerações finais}

Estados mentais extraordinários foram considerados no século XIX fenômenos naturais a partir da criação de modelos teóricos que procuravam consolidar uma concepção materialista da mente. Mesmeristas e, posteriormente, médicos ortodoxos, ao se debruçar sobre fenômenos extraordinários, tinham em comum a busca nos mecanismos fisiológicos de explicações que pudessem conferir chancela acadêmica a suas pesquisas.

Movimento praticado por médicos, o mesmerismo, entretanto, era também praticado por pessoas de distintas atividades profissionais, como atores que, nas praças, se mostravam interessados em entreter seus públicos. Tal fato provocava intensas reações no meio acadêmico. O médico que mais adiante levou seu descontentamento foi o cirurgião James Braid, ao imbuir-se da tarefa de desmitificação da prática.

Na tentativa de revelar o que havia de misterioso nas sessões magnéticas, Braid acabou por construir uma teoria que trouxe importante contribuição à profissão. Seu objetivo era investir na busca de explicações fisiológicas dos estados mentais resultantes do que ele acreditava ser uma condição cerebral. Sua teoria, uma vez cientificamente aprovada, permitiu que estados mentais antes vistos como extraordinários passassem a ser objeto de investigação científica. A explicação das alterações fisiológicas cerebrais na ocorrência desses estados mentais tornouse suficiente para livrá-los da anterior associação ao charlatanismo.

A nova concepção cerebralista para os fenômenos sobrenaturais permitiu a sistematização de uma nova nosologia, pela medicina de Paris, capaz de passar a limpo toda a história das superstições, dessa vez recontando-a por meio de um viés médico-científico e deixando pronto o terreno para a realização de nova reforma da assistência pública de saúde. Sem os freios da ideologia religiosa, a medicina encontrou campo livre para seu estabelecimento. Para isso, foi necessária a incorporação, em seus quadros nosológicos, de comportamentos e atitudes desviantes tidas como fenômenos religiosos. A localização das causas desses transtornos na fisiologia cerebral permitiu uma afirmação política dessa reforma, mas também representou a emergência de nova forma de subjetividade, em que o cérebro passa a ser a referência para a descrição de estados mentais e de comportamentos.

\section{NOTAS}

* Este artigo baseia-se em parte na dissertação de mestrado de Gonçalves (2008).

${ }^{1}$ Em 1784, o rei Luís XVI nomeou uma comissão para investigar o magnetismo animal, sendo Benjamin Franklin, embaixador americano na França, um de seus participantes. Tal comissão concluiu pela não existência do fluido, além de atestar que os efeitos desse tipo de tratamento se deviam apenas à 'imaginação excitada do paciente' e à 'imitação involuntária'. Essa desautorização oficial teve forte impacto negativo na propagação do mesmerismo por toda a Europa (Gauld, 1992).

${ }^{2}$ Magnetizadores, por meio de passes magnéticos, induziam pacientes ao estado de transe mesmérico classificado em três fases: letargia, sonambulismo e catalepsia. No sonambulismo, estado mental que foi 
descrito por Puységur (1811) e ignorado por seu mestre, o paciente apresentava faculdades extraordinárias como previsão de fatos futuros, adivinhação de diagnósticos e prescrição de tratamentos com grande êxito (Quen, 1976; Gauld, 1992).

${ }^{3}$ Nessa e nas demais citações de textos em outros idiomas, a tradução é livre.

${ }^{4}$ Alguns textos consideram James Braid médico inglês, mas, na verdade, apesar de residir e exercer sua prática profissional em Manchester, nasceu e se formou na Escócia (Gauld, 1992).

${ }^{5}$ Hipnose foi um termo criado pelo próprio Braid (1843), do grego hipnos, sono. Em seu trabalho, propôs um vocabulário próprio com vários termos distintos, entre eles neuro-hipnose; só hipnose sobreviveu à apreciação de seus pares (Gauld, 1992).

${ }^{6}$ Charcot analisou os chamados casos de divisão de personalidade comparando-os aos de sonambulismo, mas tentando localizá-los em sua nosografia da histeria. Acreditava que esses casos seriam uma transformação da terceira fase do ataque histérico, em que predominavam as atitudes passionais. Com base em alguns conceitos de Ribot, Charcot iniciou um processo de entendimento do inconsciente como um processo eminentemente cerebral (Cazeto, 2001).

${ }^{7}$ Apesar de Xavier Bichat (1771-1802) ter sido considerado o fundador da anatomia patológica no século XIX, Foucault (2004) nos lembra que nos séculos anteriores essa prática já existia. A consideração do nascimento da anatomia patológica teria sido uma reconstituição mítica do século XIX, no que esse autor considera uma ilusão retrospectiva da história da medicina.

\section{REFERÊNCIAS}

ALVARADO, Carlos. A.

Dissociation in Britain during the late nineteenth century: The Society for Psychical Research, 1882-1900. Journal of Trauma and Dissociation, McLean, v.3, n.2, p.9-33. 2002.

APA.

American Psychiatric Association. Diagnostic and Statistical Manual of Mental Disorders, $4 \mathrm{ed}$. Arlington: APA. 1994.

APA.

American Psychiatric Association. Diagnostic and Statistical Manual of Mental Diseases, 3 ed. Arlington: APA. 1980.

APA.

American Psychiatric Association. Diagnostic and Statistical Manual of Mental Disorders, 2 ed. Arlington: APA. 1968.

AZAM, Eugène.

Hypnotisme, double conscience et altérations de la personalité. Paris: J.B. Baillière et Fills Librairie. 1887.

BERNHEIM, Hippolyte.

Reponse à l'article de $\mathrm{M}$. Binet sur le livre de $\mathrm{M}$. Bernheim: De la suggestion et de ses applications thérapeutiques. Revue de l'hypnotisme experimental et thérapeutique, Paris, p.213-218. 1886.

BERNHEIM, Hippolyte.

De la suggestion dans l'état hypnotique et dans l'état de veille. Paris: Octave Doin et Fils. 1884.

BINET, Alfred.

Intensité des images. Revue Philosophique et de L'Etranger. Paris, tomo 23, p.473-497. 1889.
BRAID, James.

Neuroypnology or the rationale of nervous sleep considered in relation with animal magnetism. London: J. Churchill. 1843.

BRIQUET, Paul.

Traité clinique et thérapeutique sur l'hystérie. Paris: J.B. Baillière et Fills Librairie. 1859.

CAZETO, Sidnei José.

A constituição do inconsciente em práticas clínicas na França do século XIX. São Paulo: Escuta; Fapesp. 2001.

CHARCOT, Jean Martin.

Leçons du mardi a La Salpêtrière. Policlinique 1887-1889. Paris: E. Lecrosnier et Babé. 1889.

CHARCOT, Jean Martin; RICHET, Paul.

Les demoniaques dans l'art. Paris: Delahaye et Émile Lecrosnier. 1887.

CULLERRE, Alexandre.

Magnétisme et hypnotisme. Paris: J.B. Baillière et Fils. 1887.

DELEUZE, J.P.F.

Lettre a messieurs les membres de L'Académie de Médecine. Paris: Béchet Jeune Libraire. 1826.

FOUCAULT, Michel.

O nascimento da clínica. 6.ed. Rio de Janeiro: Forense Universitária. 2004.

GAULD, Alan.

A history of hypnotism. Cambridge: Cambridge University Press. 1992.

GONÇALVES, Valéria Portugal.

A naturalização dos fenômenos sobrenaturais e 
a construção do cérebro 'possuído': um estudo sobre a medicalização do transe e da possessão no século XIX. (Dissertação) - Mestrado.

Instituto de Medicina Social, Universidade do Estado do Rio de Janeiro, Rio de Janeiro. 2008.

MATEO, David Nofre.

En els marges de la ciencia? Frenologia i mesmerisme en una cultura industrial, Barcelona 1842-1845. Barcelona: Centre d'Estudis d'História de les Ciències. Universitat Autònoma de Barcelona. 2004.

MESMER, Franz Anton.

Mémoire sur la découverte du magnétisme animal. Paris: P.F.R. Didot. 1779.

OPPENHEIM, Janet.

The other world: spiritualism and psychical research in England, 1850-1914. Cambridge: Cambridge University Press. 1985.

De PABLO, Angel Gonzáles.

Animal magnetism in Spanish medicine (17861860). History of Psychiatry, London, v.17, n.3, p.279-298. 2006.

PUYSÉGUR, Armand MarieJacques.

Recherches expériences et observations physiologiques sur l'homme dans l'état de somnambulisme naturel et dans le sonamnbulisme provoqué par l'acte magnétique. Paris: J.G. Dentu, Imprimeur Libraire. 1811.

PUYSÉGUR, Armand Marie Jacques.

Du magnétisme animal considéré dans ses raports avec diverses branches de la physique générale. Paris: J.G. Dentu, Imprimeur Libraire. 1809.
QUEN, Jacques M.

Mesmerism, medicine, and professional

prejudice. New York State Journal of Medicine, New York, v.76, n.13, p.2218-2222. 1976.

RIBOT, Theodule.

L'hérédité psychologique. Paris: Félix Alcan. 1894.

RIBOT, Theodule.

Les maladies de la mémoire. Paris: Félix Alcan. 1881.

RICHET, Charles.

Études cliniques sur l'histéro-épilepsie ou grande histérie. Paris: Delahaye et Lecrosnier. 1881.

ROUDINESCO, Elisabeth.

Histoire de la psychanalyse en France. v.1: 1885-1939. Paris: Fayard. 1994.

SINNETT, Alfred Percy.

The rationale of mesmerism. Cambridge: The Riverside Press. 1893.

TOURETTE, Gilles de la.

Traité clinique et thérapeutique de l'hystérie d'aprés l'enseignement de La Salpêtrière. Paris: E. Plon et Nourrit. 1895.

WHORTON, James. C.

Nature cures: the history of alternative medicine in America. New York: Oxford University Press. 2002. 